\title{
"O CONHECIMENTO TEM QUE SER REPARTIDO!" NOTAS SOBRE IDENTIDADE CULTURAL, DESENVOLVIMENTO DE PRODUTOS E ARTESANATO ENTRE DESIGNERS E UM GRUPO EXTRATIVISTA DE COCO BABAÇU
}

Raiama Lima Portela

Universidade Federal do Maranhão

raiama_portela@hotmail.com

Raquel Gomes Noronha

Universidade Federal do Maranhão

raquelnoronha79@gmail.com

\author{
Nayara Chaves Ferreira Perpétuo \\ Universidade Federal do Maranhão \\ nayara_chaves@hotmail.com \\ Railde Paula Diniz Araújo \\ Universidade Federal do Maranhão
}

Ana Áurea Batista de Medeiros Santos

Universidade Federal do Maranhão

\begin{abstract}
Resumo
Este estudo, que incide sobre uma associação de grupos extrativistas do coco babaçu, envolvendo mulheres e suas famílias, nos estados do Pará, Tocantins, Maranhão e Piauí, evidencia aspectos metodológicos que posicionam os designers como mediadores de processos de inclusão social. O objetivo principal é pensar a relação estabelecida entre designers e comunidade, e a construção de novas realidades sociais a partir da instância projetual. $\mathrm{O}$ artigo apresenta a criação de produtos artesanais para serem produzidos por crianças e jovens, filhos de quebradeiras de coco babaçu, com a finalidade de ocupa-los fora dos campos - atividade representada pelo grupo social como trabalho familiar, mas [mal] interpretada pelo IBGE, que a caracteriza como trabalho infantil.
\end{abstract}

Palavras-chave: design, inclusão social, trabalho familiar, coco babaçu.

\begin{abstract}
This study, which focuses on a combination of extractive groups of babassu coconut, involving women and their families in the states of Pará, Tocantins, Maranhão and Piauí, shows methodological aspects that position designers as mediators of social inclusion processes. The main objective is to think of the relationship established between designers and the community, and the construction of new social realities from the architectural design instance. The article presents the creation of craft products to be produced by children and young people, dangerous children of babassu coconut, in order to occupy them outside the fields - activity represented by social group and family work, but [ bad ] interpreted by the IBGE which characterizes it as child labor.
\end{abstract}

Keywords: design, social inclusion, family work, babaçu coconut. 


\section{INTRODUÇÃO}

O objetivo deste artigo é apresentar formas de colaboração entre designers e o movimento social e como esta relação pode se constituir como meio para emancipação e superação de problemas sociais. O estudo, que incide sobre uma associação de grupos extrativistas do coco babaçu, envolvendo mulheres e suas famílias, nos estados do Pará, Tocantins, Maranhão e Piauí, evidencia aspectos metodológicos que posicionam os designers como mediadores de processos de inclusão social.

O NIDA (Núcleo de Pesquisas em Imagem, Design e Antropologia) foi contatado pela assessoria do Movimento Interestadual das Quebradeiras de Coco Babaçu MIQCB para propor soluções projetuais para o projeto PINDOVA. Nossa atuação deuse por meio da construção de produtos com a identidade visual que enfatiza a imagem que representa o movimento - o próprio coco.

Descrevemos as etapas metodológicas do projeto que visou à criação de produtos artesanais para serem produzidos por crianças e jovens, filhos das quebradeiras, com a finalidade de ocupá-los fora dos campos - atividade representada pelo grupo social como trabalho familiar, mas [mal] interpretada pelo IBGE, que a caracteriza como trabalho infantil.

A investigação in loco, nos campos dos quais se retiram o coco babaçu, na cidade de Esperantina, no Piauí, proporcionou a observação das ferramentas de trabalho e produtos artesanais já desenvolvidos por crianças e jovens, oportunizou a construção de um repertório visual e semântico que, ao mesmo tempo, pudesse valorizar a identidade cultural e empoderar o grupo, a partir do seu próprio conhecimento sobre a extração e o processamento do coco, para solucionar problemas sociais.

Neste estudo, refletimos sobre a participação de jovens e crianças nas comunidades dos babaçuais, preservação da memória, cultura, identidade e desenvolvimento sustentável. O objetivo principal é pensar a relação estabelecida entre designers e comunidade, e a construção de novas realidades sociais a partir da instância projetual; o papel do designer como mediador e tradutor da identidade cultural na forma de imagens e produtos é o ponto chave que direciona a discussão. Em uma situação de vulnerabilidade causada pela discrepância na interpretação de um fenômeno social - o trabalho familiar no campo - uma forma de trabalho na qual todos os integrantes da família compartilham a atividade rural/extrativista é interpretada por um mecanismo de aferição como trabalho infantil. Desta forma, estar lá, interpretar as categorias nativas e entender o ponto de vista dos implicados na questão também faz parte da atuação do designer-etnógrafo.

\section{A QUESTÃO DO TRABALHO INFANTIL}

O MIQCB nasceu em 1995 com o intuito de pressionar representantes dos governos federal, estadual e municipal a discutirem alternativas de desenvolvimento para regiões de babaçuais, promovendo o debate sobre a agricultura familiar e extrativistas, abrangendo os estados do Maranhão, Piauí, Tocantins e Pará. Esse movimento é responsável pela união das quebradeiras de coco em prol de sua autonomia, preservação do ecossistema, subsistência e de sua reprodução cultural. É 
interessante observar que esse tema é de grande importância, no que se refere ao meio ambiente e à preservação da memória cultural de populações culturais.

Segundo a assessoria do movimento no Maranhão, há sete anos, houve uma discussão interna muito intensa a partir da divulgação na imprensa sobre o trabalho infantil, apontando a atividade do babaçu como sendo uma de suas principais causas no Maranhão.

Uma vez que o MIQCB é contra o trabalho infantil e o trabalho escravo, a matéria foi considerada um equívoco, levando-os a promover um "mapa de risco" em parceria com a Organização Internacional do Trabalho (OIT) e uma equipe composta por uma antropóloga, duas epidemiologistas e um engenheiro do trabalho. Por conseguinte, chamaram o poder público para a discussão do tema.

Quando o Ministério do Trabalho convocou o MIQCB foram mostrados os resultados do mapa de risco, apontando as situações às quais as crianças estão submetidas e o mapeamento das crianças que estavam fora da escola, das crianças que não tinham transporte, das situações que as crianças iam para as escolas e que mostravam a ausência do poder público em diversas instâncias, fazendo muito pouco ou nada - para mudar aquela realidade.

O poder público criou uma lei contra o trabalho infantil muito eficiente, contudo essa lei é baseada no padrão no qual há empresas, grandes proprietários de terras, e são situações diferentes das quais essas famílias estão inseridas.

As crianças acompanham as mães na quebra do coco e durante o trabalho na roça, é uma atividade familiar, não é trabalho infantil, é considerada uma atividade cultural.

\begin{abstract}
A partir da observação em campo e diálogos mantidos com as quebradeiras de coco em diversos espaços de atuação, percebe-se que essas comunidades, até a década de 1990, não viam a presença das crianças em suas atividades produtivas como sendo um "trabalho". É a chamada política pública de erradicação do trabalho infantil que faz com que elas comecem a adotar o termo, porém não necessariamente com a mesma significação dessas políticas. (MENDES, 2009, p.11).
\end{abstract}

As integrantes do MIQCB são extrativistas, dona de casa, mulheres, mães, esposas, avós e trabalhadoras rurais. Tendo em vista que o movimento tem como foco o público feminino, o MIQCB já vinha discutindo a possibilidade de se trabalhar com o público jovem, no entanto não tinham nenhum projeto específico para a juventude. Considerando-se o problema do trabalho infantil, uma atividade que os ocupasse fora do babaçual poderia acabar com essa questão entre a lei e a realidade dessas famílias.

Surgiu uma possibilidade em um edital da Petrobras para patrocínio, que caberia a proposta de trabalhar com as mulheres e jovens a partir de 16 anos dessas comunidades, no entanto o projeto abrangeu jovens de 11 a 20 anos. Surgiu assim o Projeto PINDOVA, com o objetivo de chamar a atenção dos jovens para a possibilidade de ter oportunidades dentro da comunidade, fortalecer a juventude, a valorização da cultura e incentivar os jovens a permanecerem no campo.

Ele teve início em 2013 e foi finalizado em abril de 2016. Dele participaram 200 pessoas das áreas do Maranhão, Piauí, Tocantins e Pará. Sua denominação deve-se ao termo Pindovas atribuído às palmeiras jovens de babaçuais e, por isso, passou a representar também os jovens das comunidades do MIQCB.

Além de objetivar o envolvimento de jovens em atividades que eles tivessem interesse, o Projeto buscou a criação de uma rede virtual, instrumento de 
comunicação social para denunciar crimes ambientais, relatar e compartilhar as histórias desses jovens, ser um espaço de comunicação e integração da juventude.

\section{INSERÇÃO EM CAMPO}

A ida à cidade de Esperantina, no Piauí, tinha como objetivo conhecer, vivenciar e avaliar a produção artesanal desses jovens artesãos e propor por meio do design e da construção coletiva, o desenvolvimento de novos produtos. Como afirma Noronha (2011) nossa abordagem enfatiza o entendimento dos processos e do mapeamento das cadeias produtivas a partir da observação e da troca de experiências entre os pesquisadores e os sujeitos da pesquisa, garantindo resultado rico e representativo, em um processo de diálogo de trabalho, possibilitando o compartilhamento de saberes.

O primeiro encontro, realizado em outubro de 2015, foi nossa primeira inserção em campo. Nessa visita, foi possível avaliar e conhecer de forma preliminar a produção artesanal das comunidades. O encontro aconteceu na sede do MIQCB, em Esperantina, onde tivemos a oportunidade de conhecer os jovens, seus produtos e entender melhor a cadeia produtiva.

Conhecemos o grupo Pindova de duas comunidades, consideradas ativas na produção artesanal do Piauí. O problema que gira entorno das duas comunidades, Boi Velho e Tapuio, é a limitada produção e a variedade de produtos. Eles restringem-se a: chaveiros, colares, pulseiras, brincos, vassouras, porta-lápis e Cassimiros/Cassianes ${ }^{1}$. Observou-se durante a pesquisa deficiência no acabamento das peças, pouca diversidade e dificuldade de produção.

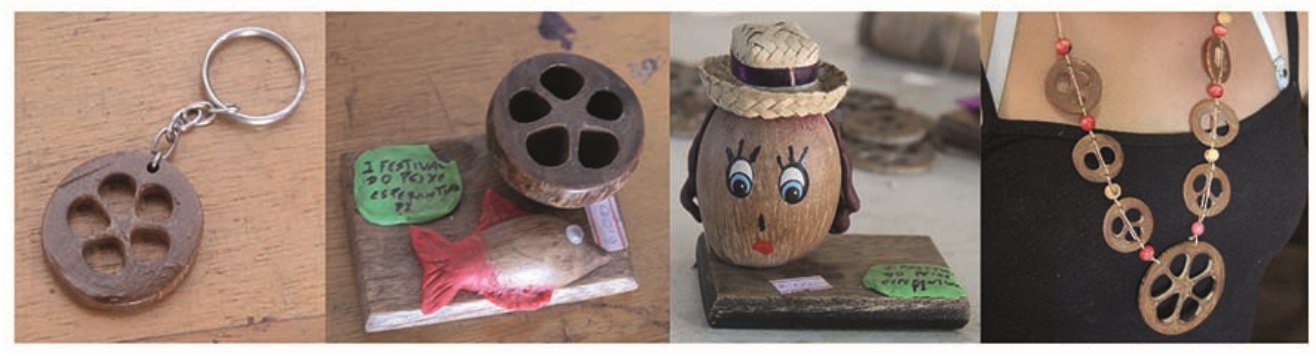

Figura 1: Produtos desenvolvidos pelos jovens do grupo Pindova.

Fonte: Elaborado pelo autor, com base na pesquisa realizada.

No intuito de entender a produção artesanal precisávamos desenhar a cadeia produtiva. Para isso, propomos uma atividade em que os próprios jovens realizaram a tarefa. Chegamos às seguintes etapas: 1) Derrubar o coco - atividade desenvolvida por mulheres, geralmente as mães, utilizando uma taboca ${ }^{2}$ ou vara; 2) Tirar as palhas do coco; 3)Tirar a casca para fazer o carvão, a massa do mesocarpo para fazer bolo, e depois quebrar-se o coco para tirar a amêndoa para fazer o azeite; 4) Serrar o coco para tirar as rodelas; 5)Passar o coco no esmeril para tirar as imperfeições; 6) Lixar a peça na mão - pode ser feito com uma lixa convencional ou com uma folha da sambaíba ${ }^{3}$; 7) Escolher, de acordo com a quantidade de furos, quais serão selecionadas

\footnotetext{
${ }^{1}$ Mascote masculino e feminino criado pelos jovens a partir do coco babaçu.

${ }^{2}$ Nome popular do bambu.

${ }^{3}$ Nome popular de uma planta cujas folhas servem de lixa.
} 
para fazer os brincos, colares, chaveiros, etc.; 8) Furar as peças, com a ajuda de uma furadeira para colocar as tranças de linha, argolas ou correntes; 9) Lixar o coco por inteiro para fazer os personagens Cassimiro e Cassiane; 10) Fazer o acabamento com verniz.

As quebradeiras reconhecem por antecipação o formato interno do coco, escolhendo o certo para cada produto. Utilizam-se as peças menores para fazer os brincos, as médias para os chaveiros e as maiores para fazer os colares.

O papel das artesãs é o de se anteciparem aos entraves da produção e conter os materiais, chegando a um ponto de equilíbrio. A característica da antecipação do resultado - o foresight, nas palavras de Tim Ingold (2012b, p.6)" que Noronha (2015) coloca em discussão, é a capacidade do artesão de antever os resultados, 'always one step a head of the material' (NORONHA, 2015; INGOLD, 2012), colocar-se à frente do material. E isso se dá pelas experiências nos espaços de vivência.

As atividades das quebradeiras de coco reforçam a sustentabilidade e a preservação ambiental. Além de aproveitarem todas as partes do coco babaçu para fazer azeite, farinha, carvão e artesanato, a atividade da quebra do coco é uma forma de manter as condições naturais da região dos cocais que, a cada dia, vem sendo ameaçada pela expansão do agronegócio. Segundo o Ministério do Meio Ambiente:

potencializar a atividade babaçueira resultaria: em melhores condições sócio-econômicas para uma considerável parcela da população dos estados do Maranhão, Tocantins, Pará e Piauí, em menor pressão do processo de expansão sobre a Floresta Amazônica e na manutenção das condições naturais que influenciam o equilíbrio dinâmico dos ecossistemas amazônicos e pré-amazônicos. (http://www.mma.gov.br/)

Para Thackara (2008), o design para a sustentabilidade se aproxima das práticas sociais. Dessa forma, o design entra nesse processo para garantir o fortalecimento da prática, através do desenvolvimento de novos produtos e da capacitação dos jovens. A importância de envolver os jovens na gestão das próprias produções abre um campo de maior possibilidade para desenvolverem seus produtos, fortalece o trabalho coletivo, dá continuidade a atividade das quebradeiras, aumenta as perspectivas econômicas e melhora a qualidade de vida dessas comunidades.

\subsection{Oficina de criatividade}

Para mapearmos o imaginário dos jovens sobre o que gostariam de produzir, realizamos uma oficina de criatividade. A ideia era estimular a imaginação e a criatividade por meio de desenhos de cenas do cotidiano, resultando na criação de novos produtos. O que nos chamou a atenção durante esse exercício foi a dificuldade de representarem a cultura. Não se tinha uma manifestação cultural forte e única do lugar que servisse de referência - para eles, os desfiles de sete de setembro e as festas juninas eram as principais. Observamos que a cidade não tinha traços identitários de manifestação cultural, levando-nos a entender que é o coco babaçu e o Movimento das Quebradeiras de Coco o que conduz e coloca em prova a identidade daquelas comunidades.

Quando se parte para o campo da imaginação, as possibilidades de produtos são infinitas, e a ampliação do repertório dentro do processo criativo é fundamental. 
Fizemos então mais um exercício de criatividade com eles. No início dessa atividade mostramos algumas referências de produtos tirados da internet, feitos com a rodela do coco babaçu. A ampliação do repertório acionou a criatividade deles, o que gerou uma maior variedade de produtos durantes o processo de criação.

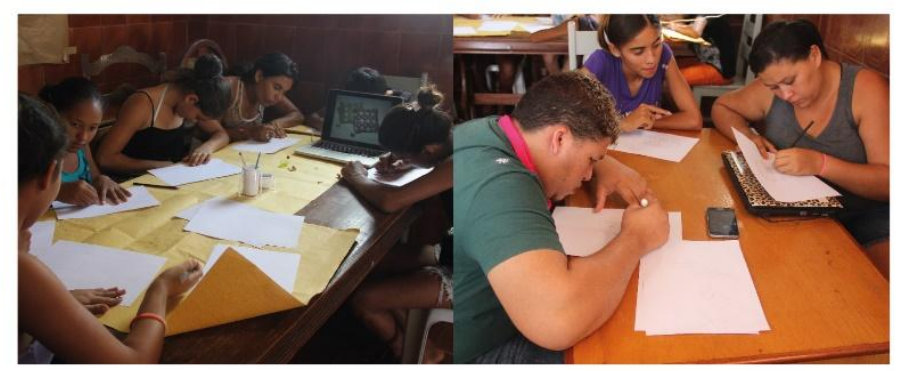

Figura 2: Oficina de criatividade.

Fonte: Elaborado pelo autor, com base na pesquisa realizada.

Em outro momento, fizemos uma divisão em grupos e cada um teria que escolher um produto para vender. $\mathrm{O}$ objetivo era saber a qualidade do produto e suas percepções sobre o que produziam. O que era para ser uma venda de produtos acabou sendo a abertura para alguns questionamentos. Uma situação relatada por uma jovem da comunidade do Boi Velho, chamou-nos a atenção. Disse que durante uma venda, um consumidor criticou uma das peças que tinham feito, dizendo que estava feio. Ela disse que ficou triste, tirou a peça da exposição e reforçou para nós a dificuldade que é para deixar a peça bem acabada. Quando questionada se achava o produto barato ela disse "é barato pelo processo", "às vezes perguntam se não pode fazer mais barato", "uma mulher deu um real a mais, porque achou trabalhoso". Esse relato reforçou um problema importante que já tínhamos observado quando analisamos a cadeia produtiva: a dificuldade de manuseio do coco, o que prejudica o resultado final do produto.

\subsection{Coco x imagem do coco}

O que vimos durante a pesquisa de campo é que não se trata, nesse caso, de um artesanato tradicional. Observamos que a produção artesanal nessas comunidades é uma atividade induzida. A atividade artesanal aparece, nesse caso, como uma alternativa de ocupar os jovens nas horas vagas. Essa característica é reforçada nas falas deles mesmos, quando questionados sobre a continuidade da produção daqui a alguns anos. As respostas variavam entre "não gostaria de continuar, não" e "quero estudar pra ser alguma coisa". O que permeia a atividade artesanal desses jovens é a pouca condição econômica. Para não os deixar ociosos e em risco de entrarem em outro tipo de atividade que possa prejudicá-los, inseri-los nessa atividade, que faz parte do seu contexto cultural, reforça a prática e a resistência das quebradeiras de coco, além de contribuir para a formação desses jovens.

Criar novos produtos é uma forma de reforçar esse movimento. E nada melhor do que representá-lo com o que temos de mais simbólico dentro da prática: o coco babaçu. Notamos durante os dias em campo, que a imagem do coco é forte. Ele movimenta a economia das quebradeiras, dele é tirado a renda mensal e é por ele que os grupos de resistência permanecem. Então, resolvemos representar o coco com 
outras possibilidades. A grande dificuldade da produção desses jovens é justamente o manuseio do coco dificultado também pela própria idade.

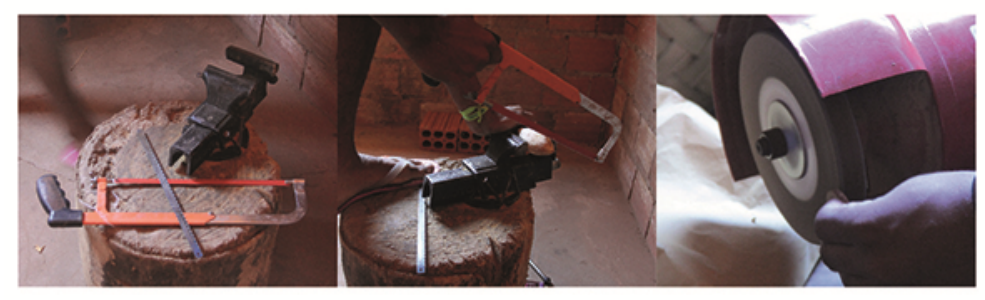

Figura 3: Processo de usinagem do coco babaçu.

Fonte: Elaborado pelo autor, com base na pesquisa realizada.

O objetivo é trazer novas oportunidades de construção da imagem do coco, não sendo necessário somente o seu uso para a elaboração de produtos, e sim o uso da sua imagem. O que queremos é minimizar o uso do coco no artesanato, sem deixar de ser o elemento de maior representatividade das quebradeiras.

Surgiram os questionamentos: como colocar em trânsito essa imagem e/ou signo? Como o designer contribui no movimento dessas representações? O que queremos é intensificar a produção artesanal, em cima da imagem do coco, propondo novas aplicações através da construção gráfica dessa imagem.

Noronha (2010) afirma que o designer, quando inserido em um campo de pesquisa, tem uma dupla tarefa acerca da categoria representação: "apreender as representações dos sujeitos de sua pesquisa, por meio da vivência no lugar da pesquisa" e representar, traduzir em linguagem gráfica (ou imagens, ou ícones da identidade cultural) as representações coletivas destes sujeitos.

A tradução em imagem, colocada por Noronha, trazendo para o universo das quebradeiras de coco, é uma forma de ressignificação da imagem de resistência, reafirmar a importância da prática e dar continuidade ao processo. A imagem, nesse caso, tem o poder de construir uma ponte que comunica essa prática a outros grupos sociais, através do transporte dos signos por meio de produtos. Quando falamos da criação a partir da imagem do coco, levamos em consideração a replicação dessa imagem em vários produtos. Como por exemplo, usá-lo como carimbo para formar estampas que podem ser aplicados em bolsas, almofadas, roupas, etc.

\subsection{Criação de produtos}

Para analisar os resultados da pesquisa e avaliarmos o que seria produzido, realizamos um workshop com os integrantes do NIDA, com a finalidade de definirmos quais técnicas e materiais seriam utilizados para o desenvolvimento dos novos produtos, em cima das observações e criações desenvolvidas durante a pesquisa de campo nas comunidades. Durante o workshop, fizemos testes com o coco e outros materiais. O objetivo foi criarmos juntos esses protótipos, baseados na capacidade produtiva dos jovens.

Escolhemos trabalhar com estampas feitas a partir do coco babaçu, replicando a imagem do coco em papel e tecido, por meio de carimbo feito com o próprio coco, para fazer cadernos artesanais e almofadas; aproveitamos também resíduos de malhas utilizando técnicas de macramê para fazer faixas de cabelo e colares; e técnicas de costura para a finalização de bolsas e almofadas. Optamos por produtos que pudessem 
permitir que cada um usasse sua criatividade, sendo na escolha das cores das malhas para as faixas de cabelo ou na composição e cores das estampas.

A intenção do workshop foi definir os produtos, criar os protótipos e depois agendar com os jovens uma oficina para ensiná-los técnicas de estampagem com o coco, técnicas de macramê, acabamentos para ajudá-los na finalização das peças, utilizando materiais fáceis de manusear e que não geram riscos durante a produção. Nosso papel, enquanto designers neste processo, é de agentes potencializadores das práticas artesanais, garantindo a emancipação dos jovens e a reprodução cultural desses movimentos tradicionais.

\section{REFLEXÕES SOBRE O PROCESSO DE DESENVOLVIMENTO DE PRODUTOS}

Aqui apresentamos as análises dos dados coletados e as representações sobre o processo de desenvolvimento de produtos por meio de uma oficina com jovens artesãos do projeto PINDOVA.

A logística montada para a realização da oficina consistiu em trazer os jovens de comunidades rurais de quebradeiras de coco babaçu para a cidade de São Luís MA, durante os dias 12 e 13 de março de 2016. Eles ficaram alojados nas dependências da sede do MIQCB, mesmo local onde se deu a oficina. Para a condução dos trabalhos foi montada uma equipe voluntária formada por pesquisadores integrantes do NIDA que tem como foco o design participativo e o design anthropology.

A oficina ocorreu para 29 jovens que já utilizam o coco babaçu para produção artesanal, vindos de comunidades do Piauí e Tocantins. Os trabalhos foram iniciados com a fala da vice-coordenadora executiva do Movimento, Maria de Jesus Ferreira Bringelo. Ela focou no estimulo às crianças e aos jovens do Projeto Pindova, sua perspectiva é a de que "o conhecimento tem que ser repartido", para participação de novas gerações protagonistas, capazes de pensar políticas públicas voltadas para o trabalho em torno do babaçual.

Confirmou-se desde um primeiro momento aquilo que já se havia identificado na pesquisa de campo: a questão da produção artesanal pelos jovens é uma atividade induzida, por conta de uma necessidade econômica com viés contingencial. A inserção deles na atividade compõe um contexto cultural de resistência das quebradeiras de coco que busca se multiplicar nas novas gerações.

Vivências e experiências de mulheres na luta cotidiana pela vida digna nas florestas de babaçu já fazem parte do cotidiano desses jovens como uma referência. Observou-se que a realização da oficina foi uma ação também estratégica no estímulo para a transformação de seus futuros e o das comunidades rurais das quais fazem parte. Logo, figurou também como uma etapa metodológica para atingir o objetivo do Projeto Pindova.

A solução projetual explicitada no capítulo anterior foi apresentada aos jovens artesãos através de uma rápida explanação da equipe do NIDA e nesse momento iniciou-se o contato de pesquisadores com os jovens.

Adélia Borges (2011) nos fala que ao design são atribuídas as premissas da projeção de objetos, mas que as técnicas podem ser apreendidas de maneiras muito variadas e que muito raramente são transmitidas formalmente na escola. Ingold (2012) afirma que a criatividade e habilidade projetual são inerentes ao ser humano e nós, pesquisadores em design, precisamos considerar os limites específicos das habilidades 
individuais, considerando a faixa etária, o acesso aos bens culturais e o repertório individual de cada ator envolvido no processo.

Por meio de técnicas de criatividade e processos manuais oportunizou-se aos jovens o contato com materiais e possibilidades de produtos. Inicialmente, eles se dividiram em grupos para melhor operacionalizar as práticas. Formaram-se três grupos, onde em cada um era desenvolvida uma técnica (pintura em tecido e em papel, macramê, encadernação e costura). Após um intervalo de tempo préestabelecido, havia um revezamento, de tal modo que ao final dos dias todos pudessem ter acesso a todas as técnicas e desenvolvessem todos os produtos propostos, sendo eles: caderno, almofada/bolsa e bijuteria.

O fator idade influenciou muito no comportamento dos participantes. De modo geral, os menos jovens mostravam-se mais interessados. Em todo o grupo, três crianças chamaram a atenção, pois participavam sob a tutela da mãe, Luciana. Ela por sua vez mostrava-se muito interessada que os filhos aprendessem, cobrando-os no processo. A filha mais velha reproduzia sua postura fazendo o mesmo com os irmãos menores. Evidenciou-se o esforço de Luciana, já na última etapa da oficina, para manter o controle da prole: "Êta menina que tá dando trabalho! Vai chamar ela ali, Marcos, que ela tá só no celular e tem é que participar das oficinas".

Este discurso também denuncia um grande concorrente das atividades desenvolvidas: o aparelho celular. Como nas comunidades de origem dos jovens o sinal de internet é muito escasso e eles estavam em uma capital, aproveitaram para manterem-se conectados. A tecnologia foi usada como recurso pelos rapazes, inclusive por aqueles que não tinham o sinal de internet, mas que insistiam em olhar mensagens antigas e fotografias. $O$ intuito era resistir à finalização das almofadas por uma postura preconceituosa velada de que costura é uma atividade feminina. Apenas quando os rapazes mais velhos começaram a fazer o acabamento das peças costuradas à mão é que os mais jovens iniciaram a técnica. Essa postura nos coloca diante de um contexto antagônico, uma vez que eles estão e são tão próximos de um movimento cujas protagonistas são mulheres. As questões de gênero, no âmbito da produção artesanal, são fatores determinantes da divisão social do trabalho, e precisamos estar sempre atentos a elas.

Juscelino, um dos jovens do Piauí, enquanto realizava os trabalhos comentou que estava com muito interesse na implantação de wifi. Seu desejo é que o sinal de internet seja roteado de tal maneira que cada jovem, através de seu celular fique conectado, pois dessa forma poderiam comercializar virtualmente, compartilhar informações relativas às quebradeiras de coco, articular a presença em feiras etc.

A atitude empreendedora também foi manifestada e o próprio Juscelino é um exemplo. Ele questionava sempre o custo das peças e no nome dos materiais utilizados. Pensando a longo prazo, comentou que em sua cidade talvez não fosse possível o acesso a alguns materiais e questionava sobre outras possibilidades. Sempre que possível, com os recursos que tinha, ele experimentava. Ao concluir seu produto, conforme orientado, buscava dar seu toque final, inovando-o. No caderno, por exemplo, acrescentou sementes à capa. Ao finalizar a produção começou a oferecê-lo aos gestores do projeto pelo preço de doze reais como um produto exclusivo e feito por ele. 


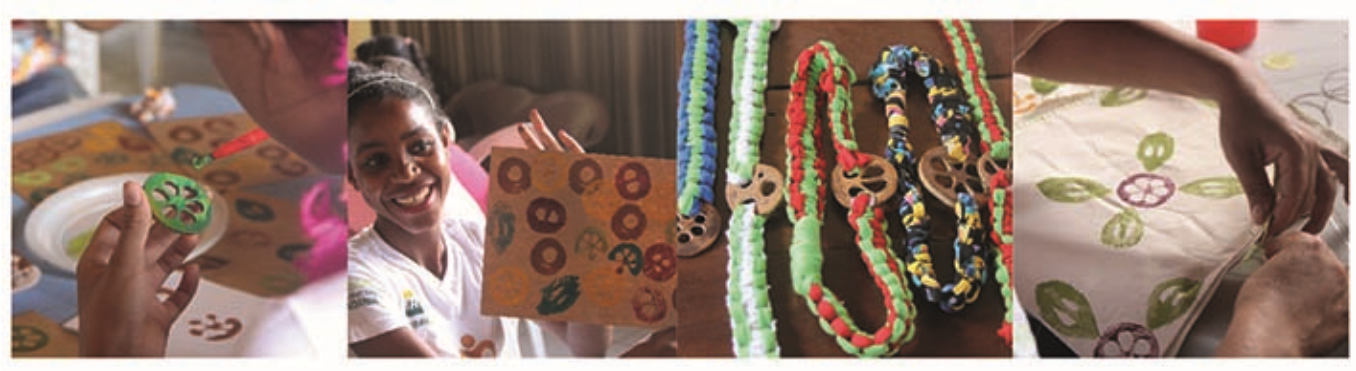

Figura 4: Produtos desenvolvidos com os jovens.

Fonte: Elaborado pelo autor, com base na pesquisa realizada.

A preocupação com possíveis clientes também foi manifestada, principalmente na oficina de macramê. Nela estimulava-se o uso de tecidos com cores variadas para facilitar a aprendizagem das laçadas. Nessa ocasião, um dos jovens do grupo de Tocantins comentou: "tem gosto para tudo, na nossa região as pessoas gostam de poucas cores". Como resultado observou-se a confecção de muitas peças monocromáticas.

"O incremento técnico passa pelo aperfeiçoamento da própria prática artesanal" (BORGES, 2011, p.66). Pode-se constatar isso ao se observar que a aplicação da técnica de pintura com carimbo de coco por um grupo que iniciou tendo o tecido como superfície ao passar para o papel acha o último mais fácil e o mesmo acontece com quem começou com o papel ao passar para o tecido. Com isso, percebeu-se que, independente da superfície carimbada, é a habilidade adquirida que faz com que a segunda experiência seja mais valorizada. Dada uma primeira impressão e ansiedade possivelmente uma técnica pode ser desprezada pelo artesão, que pode deixar de dar continuidade a ela como recurso.

A continuidade ao trabalho nas comunidades de origem é uma dúvida que persiste na mente do designer. Esta questão também é apontada por Adélia Borges (2011) como uma grande dificuldade em fazer com que o trabalho tenha significado e relevância para a comunidade local e, assim, possa ser continuado.

Uma esperança nos foi apontada por Luciana: "Nosso grupo tem mais crianças, se desde o início tivessem feito assim já tinha feito muito mais, porque sempre depende do adulto". Logo, facilitar o uso do coco babaçu nos produtos pelos jovens, respeitando sua habilidade manual de forma independente foi uma possibilidade bem-sucedida.

Ela também nos diz que: "quando participam nas feiras eles nunca vão porque não tem o que mostrar. Mas agora vai ter". Uma vez tendo sido identificadas técnicas compatíveis com os recursos, habilidades e faixa etária sem que isso se desvirtue da clara identidade do contexto de onde faz parte, espera-se, a longo prazo, confirmar essa fala e obter respostas positivas. Esta mesma promessa ouvimos numa avaliação final feita por Antônio Lee que nos diz: "cada um veio representando um grupo maior e têm a responsabilidade de socializar o que aprendeu".

O relato da falta de produção dos jovens também reflete uma situação de notório desestímulo. $O$ árduo trabalho para tornar as pastilhas de coco propícias para o uso em produtos atraentes foi substituído pela imagem do mesmo coco carimbada em tecido ou papel. Percebeu-se que o uso da pastilha de coco limitada apenas como carimbo fez com que houvesse uma transferência natural para a exploração ao máximo do recurso de sua imagem, seguindo uma noção de que quanto mais coco 
maior o valor do produto. Identificou-se que como o modelo ideal de pastilha é o mais liso possível e uniforme, assim também os carimbos foram percebidos. Em diversos momentos, houve a aplicação direta de tinta para cobrir falhas naturais deixadas pelas peças nas imagens obtidas. Diversas vezes observamos essa prática incomodando o designer que tentava interferir sem agredir mostrando possibilidades. A frase "o defeito pode ser um efeito" foi usada várias vezes sem muito sucesso. O universo cognitivo realista preponderava sobre o universo mais conceitual.

O desestímulo associado à inexperiência própria da idade foi identificado como uma dificuldade a mais refletida através da indisponibilidade para execução de trabalhos que exigiam maior tempo e dedicação. Na confecção da almofada, há a inserção de uma pastilha de coco como um detalhe agregador de valor, mas essa característica foi totalmente desconsiderada em um relato de um dos jovens: "não vou botar coquinho não, obrigado. Coragem: zero".

Durante o processo de confecção das peças, verificou-se que eles insistiam em fazer como queriam e sem seguir as recomendações. Buscou-se não interferir invasivamente nessa questão durante o processo de produção por entender que a identidade cultural tem a ver com o tempo e lugar que se vive. Nesse caso, distante da realidade do designer, e que são processadas de maneiras particulares pelos grupos e indivíduos (BORGES, 2011).

O resultado da maioria das experiências com foco na diminuição do trabalho foi frustrante, principalmente quando envolviam o acabamento, e eles foram capazes de reconhecer isso sozinhos. As peças mais bem-acabadas despertam a atenção entre eles mesmos e eram referenciadas de maneira positiva.

Deusalina, durante toda a oficina, demonstrou-se atenta aos detalhes de cada técnica e, principalmente na de macramê, cobrava-se: "tomara que eu não esqueça dos pontos". Ela comentou que a mãe faz trabalhos manuais com retalhos de malha, principalmente produzindo tapetes e que, para ela, dentre os produtos apresentados, as tiaras serão mais fáceis de serem continuadas pela facilidade de acesso ao material.

Bruna, ao fazer uma bijuteria que não ficou tão bonita quanto esperava pensou logo em desistir, quando Deusalina, que já havia passado por situação semelhante, interviu: "Mulher, não pode desistir!". Discurso similar foi feito por uma das profissionais que acompanhava o desenvolvimento da técnica, mas só foi efetivamente considerado numa interação entre pares. Nesse momento, percebeu-se o designer efetivamente como mediador, que não possui receita pronta, com papel de facilitador de conversas e estimulador de descobertas.

\section{CONSIDERAÇÕES FINAIS}

O designer em associação com a comunidade tem a chance de explorar e viabilizar não apenas as melhorias do serviço, mas também as formas como estes indivíduos se inserem no meio. A participação no Projeto Pindova, foi um desses casos em que o desafio foi além do aperfeiçoamento da força de trabalho. Efeito da união do significado com o saber fazer.

Dentre as principais questões da problemática do Projeto Pindova, estava a inserção de crianças e os jovens em atividades mais leves referente ao coco e, mesmo assim, a dificuldade de manuseá-lo manteve-se. Cortar o coco era um grande problema diante de todo o esforço físico e do perigo proporcionados por esta tarefa. 0 
designer dentro deste processo buscou introduzir um novo modo de produzir menos agressivo e mais adequado à idade e à força física desses jovens, inserindo e agregando os valores do coco e proporcionando uma noção de valorização e pertencimento a esses indivíduos.

Quando designers escolhem determinado fenômeno ou artefato pertencente a um grupo social para tangibilizá-los em imagens, deve-se observar que tal fenômeno ou artefato é uma instância dinâmica, que foi produzida, circula e é consumida na história. O valor do elemento, neste caso, atrela-se a uma forte questão de sustentabilidade e responsabilidade, não só ambiental, mas também social, partindo da necessidade de manter estas crianças e estes adolescentes fora do ócio e próximo do movimento das quebradeiras de coco e do domínio de conhecimentos e de sua própria cultura.

O designer como mediador tem a função de interpretar não apenas os significados simbólicos que se atrelam a uma produção, mas também, todos os elementos sociais, ambientais e econômicos que ladeiam estas comunidades. Entender o indivíduo se torna essencial para entender a sua produção o que, por vezes, não é interpretado de maneira exata por aqueles que executam o trabalho.

\section{REFERÊNCIAS}

BORGES, Adélia. Design + artesanato: o caminho brasileiro. São Paulo: Editora Terceiro Nome, 2011.

INGOLD, Tim. Trazendo as coisas de volta à vida: emaranhados criativos num mundo de materiais. In: Horizontes Antropológicos, Porto Alegre, ano 18, n.37, p. 25-44, jan./jun. 2012.

MANZINI, Ezio. Design, when everybody designs. An introduction to Design for Social Innovation. The MIT Press: Cambridge/London, 2015.

MENDES, Ana. A política de erradicação do trabalho infantil no contexto das comunidades tradicionais: o dilema imposto as quebradeiras de coco babaçu. Trabalho de conclusão do curso de especialização em sociologia das interpretações do Maranhão: povos e comunidades tradicionais, desenvolvimento sustentável e políticas étnicas. MA. São Luís, 2009.

NORONHA, Raquel. O designer orgânico: reflexões sobre a produção do conhecimento entre designers e louceiras em Itamatatiua - MA. São Luis, 2015. Em processo de publicação.

(org.). Identidade é valor: as cadeias produtivas do artesanato de Alcântara. São Luís: EDUFMA, 2011.

. O designer e a produção de sentido na construção de iconografias. In: BRASIL, Marcus Ramúsyo de Almeida (org.). A imagem na idade mídia: medições na imagem e o popular contemporâneo. São Luís: EDUFMA, 2010.

THACKARA, John. Plano B: o design e as alternativas viáveis em um mundo complexo. São Paulo. Saraiva: Versar, 2008.

PATROCÍNIO, Gabriel; NUNES, José Mauro (org.). Design \& Desenvolvimento: 40 anos depois. São Paulo: Blucher, 2015. 